\title{
TAHSP:-
}

The Internet Joưnal of Allied Health Sciences and Practice

A Peer Reviewed Publication of the College of Health Care Sciences at Nova Southeastern University

Dedicated to allied health professional practice and education

http://ijahsp.nova.edu Vol. 11 No. 4 ISSN 1540-580X

\section{Promoting Health and Wellbeing for People with Attention Deficit Hyperactivity Disorder: An Occupational Perspective}

\author{
Danielle Hitch, BOT GDipMtlHIthSc, MSc(AdvOccThpy), MA(Writing), PhD Candidate ${ }^{1}$ \\ Negar Lavasani, BSc(OT), MSc(Psych), PhD candidate2 \\ Genevieve Pepin, $\mathrm{PhD}^{3}$ \\ Karen Stagnitti, $\mathrm{PhD}^{4}$
}

1. Fieldwork Supervisor / Lecturer, Deakin University, Geelong, Victoria

2. PhD Student, Deakin University, Geelong, Victoria

3. Senior Lecturer, Deakin University, Geelong, Victoria

4. Professor, Deakin University, Geelong, Victoria

Australia

CITATION: Hitch D, Lavasani N, Pepin G, Stagnitti K. Promoting Health and Wellbeing for People with Attention Deficit Hyperactivity Disorder: An Occupational Perspective. The Internet Journal of Allied Health Sciences and Practice. Oct 2013. Volume 11 Number 4.

\section{ABSTRACT}

Purpose: To provide an overview of current knowledge and practice that supports an occupational perspective to health promotion for people with attention deficit hyperactivity disorder (ADHD).Method: Evidence was identified from a range of electronic databases using inclusion and exclusion criteria. Studies were subjected to a process of critical appraisal using scales for both quantitative and qualitative research, with only those ranked in the top four levels included. The scales used for this critique were the levels of evidence for quantitative research defined by the Australian National Health and Medical Research Council (NHMRC) and the Rosalind Franklin Qualitative Research Appraisal Instrument (RF-QRA). The occupational perspective on health was used as a theoretical organising structure. Results: Thirty-six studies met the criteria for inclusion. Sensory processing, fine motor control, and play emerged as areas of current knowledge and research in relation to the occupational perspective. However, adults with ADHD are poorly represented in the evidence, as were the mental health needs of this population. Conclusion and recommendations: Several areas of expertise developed by occupational therapists were identified in the literature that could provide for a health promotion approach for people with ADHD. However, more studies are required to expand this specialist knowledge and develop innovative programs that take a more positive and empowering approach to living with this condition.

\section{INTRODUCTION}

Attention deficit hyperactivity disorder (ADHD) is one of the most commonly diagnosed neuropsychiatric disorders in young people, with a worldwide prevalence of $5.29 \%$ of people aged under $18 .{ }^{1}$ It is characterised by inattention, hyperactivity, and impulsivity, and can have profound effects on individuals and their families. Despite its prevalence, ADHD remains a controversial diagnosis, with critics expressing concern about the use of stimulant medication as a primary treatment and the potential pathologising of normal childhood behaviour. ${ }^{2}$ Several changes to the diagnostic criteria are currently being considered in preparation for the upcoming fifth edition of the Diagnostic and Statistical Manual of Mental Disorders, including potentially reducing the number of symptoms required for the diagnosis of adolescents and adults, and changing the age ranges associated with onset. ${ }^{3}$ 
Occupational therapists are often called upon to work with people with ADHD, and research around enabling these clients to more fully participate in daily life first began appearing in the late $1980 \mathrm{~s} .{ }^{4,5}$ As time has passed, the profession has also begun defining its role with people with ADHD in greater detail, with increasing numbers of studies published over time. ${ }^{6}$ The building momentum in this area is highlighted by the large number $(n=19)$ of published peer-reviewed articles listed in the EBSCOHost and OTDBase databases taking an occupational perspective on ADHD since the beginning of 2010. This accounts for over half the evidence base on this topic.

Occupational therapy has a long history of using occupation to promote health, prevent illness, and meet individual needs. However, it has also been criticised for allying itself too closely with the medical paradigm, which is particularly dominant in the general discourse around ADHD.7 In contrast to the medical paradigm, an occupational perspective of health emphasises the relationship between the activities that people engage in and their overall health and wellbeing. ${ }^{7}$ It explores both the negative and positive impacts of occupation, with the intent of empowering people to reach their fullest potential. An occupational perspective of health is aligned with a health promotion approach, entails a commitment to "enable" rather than "treat," and assumes an active role for clients in managing their own health and wellbeing. 7,8

To date, no research has been published that has adopted a health promotion approach to ADHD, and the focus has remained on symptom (and usually behavioural) control. An occupational perspective on this topic can therefore offer a novel approach to working with people with ADHD, and is important in several ways. It is currently unclear how health professionals empower people with ADHD to take control of their health and/or its determinants, and an occupational perspective may help to illuminate this empowerment process. ${ }^{9}$ There is considerable resistance to the current mainstream treatments for ADHD (particularly medication), and offering an alternative evidence-based perspective provides greater choice. ${ }^{10}$ Finally, the promotion of active participation by people with $A D H D$ in the management of their condition has many potential benefits, including in reducing service and medication costs and promoting long-term recovery. It is important to note that no one approach contains all the answers for people with ADHD, and what follows should be considered as complementary to other perspectives on this condition.

The aim of this article is to perform a systematic review of recent occupational therapy knowledge and practice with people experiencing ADHD from an occupational perspective. While much of the research reported in this systematic review uses techniques more often associated with the biological view of health, it also reflects the occupational perspective of the profession. By focusing on how the health and wellbeing of these clients can be positively supported and enabled, this review will offer an outlook on this area that differs significantly from the prevailing discourse. The critical question guiding this review is "From the occupational perspective, what is the current knowledge and practice with people experiencing ADHD?"

\section{METHOD}

Articles were found using two databases: EBSCOHost (Academic Search Complete, AMED, CINAHL, Health Source Nursing/Academic Edition, Medline, PsychArticles, Psychology and Behavioural Sciences Collection, Psychlnfo and Social Work Abstracts) and OTDBase. "Attention deficit hyperactivity disorder" and "occupational therapy" were used as search terms. It has been suggested that systematic reviews should be limited to meta-analyses, randomised control trials, experimental research, and single subject studies. However, this would exclude much of the current evidence in occupational therapy. ${ }^{11}$ Therefore, a broader field of evidence was included in this review, comprising qualitative research that captures the "lived experience" of ADHD.

Studies included in this review were 1) published between 1 January 2000 and 1 July 201,; 2) published in the English language, 3) peer-reviewed, and 4) authored by at least one occupational therapist. Studies excluded from this review were 1) studies from the lowest level of the evidence hierarchy, 2) studies that included participants with ADHD but that did not report separate results for them, and 3) studies that did not directly address ADHD.

Papers that met the inclusion criteria were identified and mapped against the dimensions of occupation. They were then evaluated using two hierarchies of evidence: The Rosalind Franklin Qualitative Research Appraisal Instrument (RF-QRA) and the levels of evidence for quantitative research defined by the Australian National Health and Medical Research Council (NHMRC).12 The RF-QRA evaluates a study's standards of trustworthiness as measured through credibility, transferability, dependability, and confirmability, with Level I studies successfully addressing all four standards of trustworthiness and Level V studies not addressing any of them. ${ }^{13}$ There are also five levels of quantitative evidence defined by the NHMRC, according to the perceived robustness of the methodology used in the study. Only those studies classified above Level IV on either hierarchy have been included in this review. 


\section{RESULTS}

Seventy publications were initially identified using the above-mentioned search strategy. Of these, 34 were excluded according to the exclusion criteria, leaving 36 studies for consideration. Quantitative research (and controlled studies in particular) is the dominant form of research methodology used. The amount of published occupational therapy research into ADHD increased rapidly from 2010, and this accounts for over half of the total body of evidence. All but one of the studies focused on children or adolescents, and unless stated otherwise, this is the population referred to throughout this review. A summary of all included articles is provided in Table 1.

\begin{tabular}{|c|c|c|c|c|c|c|}
\hline \multicolumn{7}{|c|}{ Table 1. Studies Included in this Systematic Review } \\
\hline \multirow[t]{2}{*}{ Authors } & \multirow{2}{*}{ Method } & \multicolumn{3}{|c|}{ Sample } & \multirow[t]{2}{*}{ Gender } & \multirow{2}{*}{$\begin{array}{l}\text { Level of } \\
\text { Evidence }\end{array}$} \\
\hline & & $\begin{array}{c}\text { People with } \\
\text { ADHD }\end{array}$ & $\begin{array}{c}\text { People without } \\
\text { ADHD }\end{array}$ & Other & & \\
\hline Bart et al. & Cohort & 18 & & & Mixed & IIII \\
\hline Brossard et al. & $\begin{array}{l}\text { Systematic } \\
\text { review }\end{array}$ & $\mathrm{N} / \mathrm{A}$ & $\mathrm{N} / \mathrm{A}$ & $\mathrm{N} / \mathrm{A}$ & $\mathrm{N} / \mathrm{A}$ & I \\
\hline Cheung \& Siu & Control & 114 & 1840 & 72 & Mixed & III \\
\hline Cordier et al. & Control & 112 & 238 & & Mixed & IIII \\
\hline Cordier et al. & Control & 112 & 126 & & Mixed & III \\
\hline Cordier et al. & Control & 105 & 105 & & Mixed & IIII \\
\hline Cordier et al. & Control & 112 & 238 & & Mixed & III \\
\hline Cronin & Phenomenology & 22 & & 22 & $\begin{array}{c}\text { Female } \\
\text { (Mothers) }\end{array}$ & II \\
\hline Engel-Yeger \& Ziv-On & Control & 29 & 29 & & Male & III \\
\hline Gol \& Jarus & Pre/post & 27 & 24 & & Mixed & IV \\
\hline Hahn-Markowitz et al. & Pre/post & 17 & & & Mixed & IV \\
\hline Iwanaga et al. & Matched cases & 46 & 46 & & Male & IIII \\
\hline Lane et al. & Control & 39 & 46 & & Mixed & III \\
\hline Lavasani \& Stagnitti & Control & 26 & 29 & & Mixed & III \\
\hline Lee et al. & Control & 23 & 38 & & Mixed & IIII \\
\hline Leipold \& Bundy & Control & 25 & 25 & & Mixed & IIII \\
\hline Linder et al. & Control & 80 & 78 & & Mixed & III \\
\hline Nikharge \& Mulgaonkar & Pre/post & 22 & & & Mixed & IV \\
\hline Pfeifer et al. & Control & 16 & 16 & & Mixed & IIII \\
\hline Pfeiffer et al. & $\begin{array}{l}\text { Randomised } \\
\text { control trial }\end{array}$ & 63 & & & Mixed & II \\
\hline Pollak et al. & $\begin{array}{l}\text { Double blind, } \\
\text { placebo } \\
\text { controlled, } \\
\text { crossover }\end{array}$ & 27 & & & Mixed & II \\
\hline Poulsen et al. & Control & 20 & & & Male & III \\
\hline Reynolds et al. & Control & 24 & 24 & & Mixed & III \\
\hline Rosenblum et al. & Control & 12 & 12 & & Mixed & IIII \\
\hline Schilling et al. & $\begin{array}{l}\text { ABAB interrupted } \\
\text { time series }\end{array}$ & 3 & & & Mixed & IV \\
\hline Segal & Grounded theory & 17 & & & $\begin{array}{c}\text { Mixed } \\
\text { (Families) }\end{array}$ & II \\
\hline Shaffer et al. & Pre/Post & 56 & & & Males & IV \\
\hline Shen et al. & Control & 15 & 15 & & Male & III \\
\hline Shen, Lee \& Chen & Control & 21 & 21 & & Mixed & \\
\hline Shimoni et al. ${ }^{*}$ & Control & 25 & 25 & & Male & IIII \\
\hline Tsai et al. & Matched cases & & & 108 & Mixed & III \\
\hline VandenBerg & $A B$ design & 4 & & & Mixed & IV \\
\hline Wilkes et al. & Matched cases & 15 & 15 & & Mixed & IIII \\
\hline Wu et al. & Control & 31 & 30 & & Mixed & III \\
\hline Yochman, Ornoy \& Parush & Control & 49 & & & Mixed & IIII \\
\hline
\end{tabular}

${ }^{*}$ This was the only study with adult subjects 
Despite the relative homogeneity of methods, five distinct focal points for the occupational perspective on health and wellbeing for people experiencing ADHD were found. These were sensory processing, play, fine motor control, interpersonal relationships and cognitive function.

\section{Sensory Processing}

Sensory processing has been the focus of nine recent studies, which indicates this factor may have an impact on the abilities, capacities and occupational engagement of people with ADHD. Five of these studies indicated that children with ADHD may have different sensory profiles to normally developing children. A range of assessment tools have been used to explore this issue including both the full and short Sensory Profile, the Japanese Version of the Miller Assessment for Preschoolers, the Sensory Over-Responsivity Inventory, and physical measurements of cortisol and electrodermic activity. This range of measures may be reflected in the various sensory processing difficulties that have been identified, including signs of sensory processing disorder, differences in physical recovery from sensory challenges, poorer sensory motor performance (particularly for equilibrium and postural control), poorer general performance, a similar profile to children with autistic spectrum disorders, and high levels of co-morbidity with sensory over-responsivity. ${ }^{14-17}$

Conversely, areas of relative strength have been found in sensory processing for children with ADHD. This group were found to perform within the typical range for taste/smell sensitivity and visual/auditory sensitivity, and also for simple rapid movements and non-motor visual perception. 15,16 There is currently contradictory evidence around potential difficulties with auditory processing. Cheung and Siu found that children with ADHD were particularly likely to experience deficits in this area, while Iwanaga et al identified simple auditory memory as an area of better performance. ${ }^{14,15}$ While both of these studies used controlled designs, the sample of the Iwanaga et al study was all male; this could potentially be an influencing factor.

The potential effect of these sensory difficulties on occupational engagement is highlighted in comparison to other characteristics and abilities. Engel-Yeger and Ziv-On found that children with inattentive ADHD were significantly less likely to prefer recreational activities than were normally developing children or those with the hyperactivity subtype. ${ }^{16}$ Correlations were also found between many aspects of the sensory profile and participation preferences, which could relate to the physical environments in which these occupations occur. ${ }^{16}$ Lane et al and Reynolds et al found that co-morbid sensory over-responsivity in children with ADHD was related to higher (though not clinically significant) levels of anxiety, and that this may be a moderating factor distinguishing between subtypes of ADHD. ${ }^{17,18} \mathrm{~A}$ person with ADHD may therefore have a particular configuration of abilities and capacities that may exert either a positive or negative impact on their health through occupation.

The potential for promoting health and wellbeing by ameliorating and compensating for these differences was addressed in a series of studies that used sensory processing as a medium for intervention. Nikharge and Mulgaonkar reported significant improvements in arousal, somatosensory systems, and praxis following treatment specifically targeting sensory processing. ${ }^{19}$ The authors concluded that somatosensory, vestibular, visua, and auditory systems are essential to the performance of people with ADHD, and recommended the use of the Alert Program $®$ as an adjunct treatment (as did Young). ${ }^{20}$ The Alert Program $®$ is a self-regulation intervention developed by two American occupational therapists. However, it has not been subjected to research evaluation to date. There are significant gaps in the Nikharge and Mulgaonkar study, with only a very brief description of the intervention and a relatively small sample..$^{19}$

Two studies of specialised seating for people with ADHD have also shown promising results. In one study, therapy balls and regular chairs were used in an alternating pattern in a classroom, with the students' behaviour observed by the researchers and feedback sought from both teachers and students. ${ }^{21}$ The other form of seating investigated was Disc ' $O$ ' Sit seating, which was the subject of a randomised control trial. ${ }^{22}$ Disc ' $O$ ' Sit seating is a round inflatable rubber cushion that is placed on the student's usual chair. After children were randomised to treatment and control groups, they used this seating in the classroom for two weeks. Significant improvements were recorded in both studies for behaviours such as remaining in seats, writing legibly, and attention to tasks. In the therapy ball study, teachers were also found to be supportive of the equipment's use, and all students in the class indicated that they preferred the balls. ${ }^{21}$ Despite the robust methodology used in the Disc 'O' Sit study, there were several limitations. The participants were identified by teachers as having attention problems using an unvalidated screening tool, and both the pre and post scoring were completed by the same teachers. The evidence around the effectiveness of seating interventions must therefore be interpreted with some caution.

Another piece of equipment that has been the subject of research is weighted vests. An $A B$ design study to assess the effectiveness of weighted vests in a clinical setting recommended weights as close to $5 \%$ of the child's total body weight as possible..$^{23}$ In a school setting, on-task behaviour increased by 18 to $25 \%$ in all students, and three of the four participants asked to wear the vest outside the observation periods. This indicates this treatment may be both effective and acceptable to children

(c) The Internet Journal of Allied Health Sciences and Practice, 2013 
with ADHD, although further studies of effectiveness are required. While the body of evidence is small, there are some signs that adaptive equipment can make a positive impact on the occupational engagement of people with ADHD.

\section{Play}

Play is the fundamental occupation of childhood, and eight studies of play were found focusing on the experience of children with ADHD. Once again, these children appear to have a particular configuration of abilities and capacities that influence their experiences of play. Leipold and Bundy revealed that children with ADHD found internal control, intrinsic motivation and framing problematic during play, while Cordier et al found that children with the inattentive subtype of ADHD had significantly more difficulty in concentrating on play than was predicted.24,25 However, the children persisted with activities that they found motivating. Cordier et al also found that overall scores on the Test of Playfulness were lower for children with ADHD, particularly for sharing, support, intensity, skill of social play and skill in responding to cues.25,26 These children seemed to particularly struggle with the intensity of play interactions and with reading the cues of others in these situations, which the authors attributed to a delay in the development of the ability to decentre.

Strengths in play were also identified in all of these studies. Children with ADHD were found to be good at mischief making, teasing/joking, and clowning, while those with hyperactive/impulsive and combined subtypes are more extroverted, less selfconscious, and more animated. ${ }^{24,27}$ In one study, they also performed significantly better than typically developing children for negotiating, and sought play interactions just as much as the control group. ${ }^{26}$ Despite these areas of difference, the last study also found no significant differences between children with ADHD and the control group in outcome measure items specifically related to the primary symptoms of ADHD. These children are therefore able to express themselves through play successfully in some circumstances, albeit in a style of play that may be more rambunctious and active than usual.

The impact of these children's characteristics in play may also affect their playmates. One study investigated the play behaviour of normally developing children while both playing with a normal peer and playing with a child with ADHD. ${ }^{27}$ While measures were taken to ensure the playmates of the children with ADHD were typically developing, their outcome measures closely resembled those children in terms of lacking empathy. The authors propose this may be due to the dominance of children with ADHD in play, and potentially with a co-morbidity factor, as many of the children chose to play with their siblings.

The abilities and capacities identified above appear to lead children with ADHD to engage in play differently. A model of playbased intervention for children with ADHD was developed, initially based on literature review, but then refined through a controlled study. ${ }^{28}$ During this development, it was found that the hallmark symptoms of ADHD could affect play but did not account for play ability overall. Cordier et al recommend that play interventions focus on intrinsic motivation and the development of empathy, and that peers and siblings be co-opted to assist with therapy (although the ethical and potentially stigmatising consequences of this are not discussed). ${ }^{28}$ The model itself links the symptoms of ADHD with elements of playfulness, and suggests a series of play enablers to encourage participation and success. The reframing of this model following empirical research supports its relevance and robustness in relation to clinical practice, as does its easy applicability to practice.

Two further studies have found significant differences in how children with ADHD engage in play. The Children's Play Behaviour Questionnaire was used to investigate the play preferences of children with ADHD and typically developing children from Brazil.29 Both groups preferred to play with siblings and classmates over parents, but the children with ADHD preferred toys and play activities that could be used alone and were structured with rules. These children also said they preferred to play at school rather than on the street, and chose safer and more boundaried play spaces. Similar findings were highlighted by Shimoni et al, who explored the leisure participation of boys with ADHD using the Children's Assessment of Participation and Enjoyment. ${ }^{30}$ These boys participated in more formal activities, but expressed significantly less enjoyment of them. These boys also scored significantly lower for participation intensity and engaged in significantly less social, skill-based, and self-improvement activities.

Given its social nature, play is also a key occupation for developing a sense of belonging. In a study into a play intervention, children with ADHD were paired with a normally developing playmate. ${ }^{31}$ Seven weekly 40 -minute sessions were provided, using both video self-modelling and graded therapist modelling. Both groups of children improved in their social play using this intervention, with modelling supported as effective for developing reflection. This indicates that children with ADHD need to first learn skills in reflection and metacognition before they can benefit from interventions that aim to develop their social skills. 


\section{Fine Motor Control}

The abilities and capacities of people with ADHD for completing fine motor tasks have been the focus of two studies by occupational therapists. Lavasani and Stagnitti surveyed a range of fine motor skills (such as pencil speed, scissor work, and pegboard activities) and found that children with ADHD performed more poorly than typically developing children on eight of the nine skills assessed. ${ }^{32}$ While this study used activities that approximated occupations completed in real life, another study on this topic used a pursuit test with a stylus on a tablet computer. ${ }^{33}$ Concerning motor flexibility, it was found that children with ADHD moved and accelerated more quickly, but performed with poorer accuracy and control. This lack of accuracy became even more apparent at higher speeds, although their speeds of movement varied regardless of the speed of the object they were pursuing.

Stimulant medication is currently a widespread treatment for ADHD, and four studies by occupational therapists have relevance to its effect on functional performance. In a study in which none of the participants were on medication, children with ADHD were found to perform differently to normally developing children across a range of fine motor skills. ${ }^{34}$ These participants wrote less legibly, spent more time with their pen on the paper, took longer to write, and displayed poorer motor skills and visual-motor integration. These results might be expected in people not taking medication, but the three studies in which participants were taking methylphenidate (Ritalin) also found substantial difficulties with fine motor control. The activities used to assess this included a virtual reality continuous performance test, handwriting, and the items on the Movement Assessment Battery for Children. $35-37$

Although a positive effect on fine motor control was found in all three studies, these improvements were not sufficient to enable children with ADHD to overcome all of their difficulties with these tasks. Pollak et al found that children evaluated one hour after taking their medication experienced significant improvement in omissions and reaction times, but did not improve on all aspects of performance in comparison to children who had taken a placebo. ${ }^{36}$ For children with ADHD and co-morbid developmental coordination disorder (DCD), significant improvement was found for aspects of motor control that rely on attention (such as dexterity, ball skills, and dynamic balance). However, their overall performance remained poor, and a clinically significant improvement was found in only one-third of the participants. ${ }^{37}$ Rosenblum et al found that children with ADHD performed significantly better for general outcome measure scores and "in air" time during a paragraph copying task. ${ }^{35}$ However, no significant difference was noted for other aspects of the task (such as speed, spatial arrangement, and legibility), and the treatment group took significantly longer to write than did the control group. Given the quality of these studies (one Level I, two Level III), this evidence can be trusted to guide practice in most cases.

A further study by Shaffer et al focused on the motor regulation of people with ADHD using the Interactive Metronome® computer program. ${ }^{38}$ This program simulates the action of a musical metronome to indicate the user's temporal accuracy when performing tasks. This training had been shown to be influential on skills beyond motor regulation, and the study by Shaffer et al found improvements in attention, language processing, reading, and parental perception of aggression regulation. Boys of the targeted age were easily engaged in the computer game, but no further research has demonstrated effectiveness for girls or other populations. Collectively, the studies seem to indicate that people with ADHD perform fine motor control activities differently to others, even when the primary symptoms of their disorder are treated by medication.

\section{Interpersonal Relationships}

Studies addressing the relationship people with ADHD maintain with others are relevant to both their innate skills and abilities and the ways in which they use them. One study focused on social skill development for children with ADHD using a group training intervention..$^{39}$ This social group ran for 15 weeks and included a parallel parents group. Using the Assessment of Motor and Processing Skills, the researchers initially found many differences between the children with ADHD in their sample and typically developing children. However, these differences had disappeared by half way through the intervention and were sustained following the completion of the group. Given that this outcome measure also addresses motor skills, it suggests a more general benefit to this form of intervention.

Two further studies focused on the lived experience of the parents of children with ADHD. A study by Segal used grounded theory with families, focusing on the parenting role. ${ }^{40}$ Mothers were found to do more than one occupation at a time (enfolding), and took some elements of a task out for later performance by either themselves (temporal unfolding) or someone else (unfolding by inclusion). However, the focus in these studies on the parents of children with ADHD exclusively means that it is not possible to discern whether these are unique practices to this group of mothers. Another perspective on mothering children with ADHD was provided by Cronin, who completed a study comparing these mothers' experiences with those of the mothers of children with cystic fibrosis. ${ }^{41}$ Cronin found that the hidden nature of ADHD presented particular challenges, and that the mothers of children with ADHD were unable to utilise the structured routines and social support available to parents of children with other hidden disabilities. Management of ADHD using specialised routines led to positive self-appraisal, while the emergence of ADHD

(c) The Internet Journal of Allied Health Sciences and Practice, 2013 
through challenging behaviour led to mothers having more negative views of both themselves and their children. Occupational therapists working with these families are advised that recommendation around strategies and routines must be compatible with and customised to the family's situation and routines. Given that both of these studies were Level II, this advice can be trusted to guide practice.

\section{Cognitive Function}

The cognitive function of people with ADHD relates directly to the capacities and abilities that form a part of their identity. While attention deficit is a hallmark of ADHD, very few studies focused on it as a functional problem. Two outcome measures have been tested for psychometric properties that relate to this symptom: the Test of Variables of Attention (TOVA) (visual) and the Hebrew version of the Behavioural Rating Inventory of Executive Functions (BRIEF) assessment.42,43 Both measures were found to discriminate validly between people with ADHD and those without. The TOVA was also found to have satisfactory internal consistency and convergent validity. Both studies found significant differences in performance between children with ADHD and typically developing children. The TOVA identified poorer performance in all of the areas assessed, while the BRIEF found that working memory scores were highly predictive of the presence of ADHD. Linder et al also found that people with the inattention subtype performed significantly worse for metacognition and global executive function, although executive dysfunction itself only correlates with and does not overlap ADHD. ${ }^{43}$ Further, Wu et al found that children with ADHD performed significantly worse than typically developing children in response times, which might indicate an initial delay before the rapid movement and acceleration identified in other studies. ${ }^{42}$

One controlled study of inhibition control of a motor response and error processing used a computerised stop signal task. ${ }^{44}$ While boys with ADHD were similar in skill to the controls for detecting errors, they found it more difficult to evaluate the error consciously and therefore performed less effectively. They also had difficulties with selective attention, inhibitory control, and error processing, suggesting a complex relationship between several different cognitive factors. A lack of rigorous studies into the relationship between neuroimaging findings and motor disturbances in children with ADHD was noted by Brossard-Racine, Majnemer, and Shevell in their systematic review of this topic. 45 The studies that were found all proposed different physical mechanisms; thus, at this time, the most appropriate approach to assessment and treatment remains focusing on clinical manifestations.

None of the four studies cited above has linked its findings to specific occupations or activities. This is relatively unusual in occupational therapy research, and may be a result of the influence of other research traditions within multidisciplinary research teams. However, a Taiwanese study examined the link between inattention and poorer performance of handwriting by focusing on the behavioural aspects of handwriting. Children using Traditional Chinese as their written language were rated by their parents for handwriting and placed into a proficient or non-proficient group according to proficiency in spelling homophones. ${ }^{46}$ While there were no differences between those proficient in spelling homophones and those who had difficulties on many of the measures of writing, there was a significant difference in regards to levels of inattention.

The longitudinal aspects of occupational engagement are crucial to the dimension of becoming, as performance over time leads to changes that can move people closer to their hopes and aspirations. An intervention known as Cog-Fun (Cognitive-Functional Treatment) is targeted at developing executive functions in children to assist them to achieve their occupational goals. ${ }^{47}$ The treatment is administered over 10 weekly sessions of one hour, along with homework to complete with parents at home. This evaluation study found that significant improvements occurred and were maintained on outcomes related to behaviours, planning, and goal setting. Executive dysfunction has been found to be prevalent in boys with ADHD, as described through both parent report and observations of functional performance. ${ }^{48}$ Shimoni et al advocate for both the child's perceptions and parents' reports to be included in the assessment of executive dysfunction, and argue that both groups should be provided with strategies that assist them to overcome these difficulties in daily life. ${ }^{48}$

The only study in this review to focus on adults with ADHD investigated an office-based hazard perception intervention for male drivers with the condition. ${ }^{49}$ The intervention was video-based and tailored to the needs of people with ADHD in terms of its instructional aspects and exercises. The control group was only shown the instructional video, and this training was found to improve hazard response times significantly in the treatment group. Adults with ADHD are a group that is underserved by occupational therapists. Nonetheless, this condition often persists past childhood, and the profession does assess and treat functional problems across the lifespan. 


\section{DISCUSSION}

The results of this review demonstrated that sensory processing, play, fine motor control, interpersonal relationships, and cognitive function are areas of particular interest and expertise for the occupational perspective of health. However, there is a lack of occupational perspective focus in the current body of research in favour of a bio-psycho-social framework in which people (usually children) with ADHD are passive recipients of assessment and treatment. Occupational therapists, as specialists in the occupational perspective on health, tend to see themselves as "enablers" and "advocates" for their client. However, this stance is either yet to be adopted for this group of clients or is not reflected in current literature.

The occupational perspective around knowledge and practice for people living with ADHD has rapidly developed over the past decade and particularly over the past two years. Currently, the best known aspects of occupation for people with ADHD are their innate skills and abilities. It seems relatively clear that people with ADHD experience the world differently than others, and that they have a specific set of abilities and capacities that affect their health through occupation. A number of interventions are being developed to address the functional problems associated with ADHD, and these are showing promise. However, many of these interventions (particularly those based around sensory processing) focus on the ephemeral aspects of occupational engagement. Thus, more longitudinal studies are needed to ensure that the gains made are retained. Deficits in the evidence base for sensory processing and integration have been highlighted by paediatricians. ${ }^{50}$ Several studies reviewed here have indicated that a focus on the symptoms of the disorder will not address all of the occupational problems experienced by people with ADHD. A holistic and multi-modal approach might be more effective.

For people with ADHD to achieve their greatest health potential, they must improve their control over the factors (including the occupational factors) that determine their health. While further research is undoubtedly needed, the current evidence suggests that there is potential for offering interventions that provide greater control for these clients over their sensory processing, play behaviours, fine motor control, interpersonal relationships, and cognitive function. Therapeutic interventions, compensatory techniques and environmental modifications that may improve the occupational engagement of people with ADHD are already available, and could be provided to both children and their families from a perspective of education and empowerment.

\section{CONCLUSION}

While the evidence presented in this review provides a good basis for the occupational perspective on ADHD in some areas, there are several directions that require further pursuit. Further effectiveness studies using robust methods are recommended along with more qualitative studies that could provide valuable insights, particularly from a client's point of view. Further development of the evidence base through the production of evidence-based guidelines that explicitly encourage a health promotion approach would be useful, although this would require consensus data to be completed due to the many gaps identified. In particular, these guidelines should be multidisciplinary, incorporating all available approaches and explicitly addressing participation and engagement using multiple methods to encompass the array of evidence available.

The contribution of occupational therapy to knowledge and practice with people with ADHD has to date focused on their innate skills and abilities, and to a lesser extent, on their occupational engagement. An understanding of how people with ADHD experience the world has now been gained, and interventions are evolving to enable them to participate in meaningful occupations far more effectively. However, our understandings of how people with ADHD become and belong are still in their infancy. While the evidence base is growing, occupational therapy will not be able to offer comprehensive and holistic evidencebased support for people with ADHD until all dimensions of occupation-including goals and aspirations and social connections-are more fully addressed. Further, an occupational perspective approach that does not equally address all of these dimensions of the occupational determinants of health is unlikely to lead to better occupational engagement for people with ADHD.

\section{REFERENCES}

1. Polanczyk G, de Lima MS, Horta BL, Biederman J, Rohde LA. The worldwide prevalence of ADHD: a systematic review and metaregression analysis. Am J Psychiat. 2007 June;164(6):942-8. [PMID 17541055]

2. Diller L, Why the controversy over ADHD won't 'go away'. In: Attention deficit hyperactivity disorder: concepts, controversies, new directions. New York: Informa Healthcare; 2008. p. 323-9.

3. Coghill D, Seth S. Do the diagnostic criteria for ADHD need to change? Comments on the preliminary proposals of the DSM-5 ADHD and disruptive behavior disorders committee. Eur Child Adoles Psy. 2010 Nov 25;20(2):75-81. [PMID 21107871]

4. Burgess PW, Mitchelmore S, Giles GM. Behavioral treatment of attention deficits in mentally impaired subjects. Am J Occup Ther. 1987 Aug;41(8):505-509. [PMID 3434602] 
5. Scholle-Martin S. Application of the Model of Human Occupation: assessment in child and adolescent psychiatry. Occup Ther Ment Health. 1987;7:3-22.

6. Chu S. Occupational therapy for children with Attention Deficit Hyperactivity Disorder: a survey on the level of involvement and training needs of therapists. Bri J Occup Ther. 2003 May;66(5):209-218.

7. Wilcock A. An occupational perspective of health. 2nd ed. Thorofare(NJ): SLACK Inc.; 2006.

8. Scaffa ME, Reitz SM, Pizzi MA. Occupational therapy in the promotion of health and wellness. Philadelphia: FA Davis Co.; 2010.

9. World Health Organisation [Internet]. The Bangkok Charter for health promotion in a globalized world; c2005. [cited 2013 Jun 17]. Available from: http://www.who.int/healthpromotion/conferences/6gchp/bangkok_charter/en/.

10. Malacrida C. Medicalization, ambivalence and social control: mothers' descriptors of educators and ADD/ADHD. Health. 2004 Jan;8(2):61-80. [PMID 15018718]

11. Taylor C. Evidence-based practice for occupational therapists. Oxford: Blackwell; 2007.

12. National Health and Medical Research Council [Internet]. How to use the evidence: assessment and application of scientific evidence; c2000. [cited 2013 Jun 17]. Available from: http://www.nhmrc.gov.au/guidelines/publications/cp69.

13. Henderson R, Rheault W. Appraising and incorporating qualitative research in evidence-based practice. J Phys Ther Educ. 2004;18(3):35-40.

14. Cheung PP, Siu AM. A comparison of patterns of sensory processing in children with and without developmental disabilities. Res Dev Disabil. 2009 Nov-Dec;30(6):1468-80. [PMID 19665348]

15. Iwanaga R, Ozawa H, Kawasaki C, Tsuchida R. Characteristics of the sensory-motor, verbal and cognitive abilities of preschool boys with attention deficit/hyperactivity disorder combined type. Psychiat Clin Neuros. 2006 Feb;60(1):37-45. [PMID 16472357]

16. Engel-Yeger B, Ziv-On D. The relationship between sensory processing difficulties and leisure activity preference of children with different types of ADHD. Res Dev Disabil. 2011 May-June;32(3):1154-62. [PMID 21324640]

17. Lane SJ, Reynolds S, Thacker L. Sensory over-responsivity and ADHD: Differentiating using electrodermal responses, cortisol, and anxiety. Front Integr Neurosci. 2010 Mar 29;4(8). [PMID 20556242]

18. Reynolds S, Lane SJ, Gennings $C$. The moderating role of sensory overresponsivity in HPA activity: a pilot study with children diagnosed with ADHD. J Atten Disord. 2010 Mar;13(5):468-78. [PMID 19372496]

19. Nikharge T, Mulgaonkar KP. Attention deficit hyperactivity disorder: a sensory perspective. Indian J Occup Ther. 2002 AugNov; $34(2)$.

20. Rodger S. Commentaries: the role of the occupational therapist in attention deficit hyperactivity disorder: a case study. Int $J$ Ther Rehabil. 2007;14(10):454-9.

21. Schilling DL, Washington K, Billingsley FF, Deitz J. Classroom seating for children with attention deficit hyperactivity disorder. Am J Occup Ther. 2003 Sep-Oct;57(5):534-41. [PMID 14527115]

22. Pfeiffer B, Henry A, Miller S, Witherell S. Effectiveness of Disc 'O' Sit cushions on attention to task in second-grade students with attention difficulties. Am J Occup Ther. 2008 May-June;62(3):274-81 [PMID 18557003]

23. VandenBerg NL. The use of a weighted vest to increase on-task behavior in children with attention difficulties. Am J Occup Ther. 2001 Nov-Dec;55(6):621-8. [PMID 12959226]

24. Leipold EE, Bundy AC. Playfulness in children with attention deficit hyperactivity disorder. Occup Ther J Res. 2000 Winter;20(1):61-82.

25. Cordier R, Bundy A, Hocking C, Einfeld S. Comparison of the play of children with attention deficit hyperactivity disorder by subtypes. Aust Occup Ther J. 2010 Apr;57(2):137-45. [PMID 20854579]

26. Cordier R, Bundy A, Hocking C, Einfeld S. Empathy in the play of children with attention deficit hyperactivity disorder. OTJROccup Part Heal. 2010;30(3):122-32.

27. Cordier R, Bundy A, Hocking C, Einfelf S. Playing with a child with ADHD: a focus on the playmates. Scand J Occup Ther. 2010 Sep;17(3):191-9. [PMID 19670080]

28. Cordier R, Bundy A, Hocking C, Einfelf S. A model for play-based intervention for children with ADHD. Aust Occup Ther J. 2009 Oct;56(5):332-40. [PMID 20854539]

29. Pfeifer T, Terra LN, dos Santos JL, Stagnitti KE, Panúncio-Pinto MP. Play preference of children with ADHD and typically developing children in Brazil. Aust Occup Ther J. 2011 Dec;58(6):419-28. [PMID 22111644]

30. Shimoni M, Engel-Yeger B, Tirosh E. Participation in leisure activities among boys with attention deficit hyperactivity disorder. Res Dev Disabil. 2010 Nov-Dec;31(6):1234-9. [PMID 20705424]

31. Wilkes S, Cordier R, Bundy A, Docking K, Munro N. A play-based intervention for children with ADHD. Aust Occup Ther J. 2011 Aug;58(4):231-40.

32. Lavasani NM, Stagnitti K. A study on fine motor skills of Iranian children with attention deficit/hyper activity disorder aged from 6 to 11 years. Occup Ther Int. 2011 Jun;18(2):106-14. [PMID 21608061] 
33. Lee I-C, Hung C-C, Yang W-H, Chen-Sea M-J, Tsai C-L. The pursuit flexibility of children with attention deficit / hyperactive disorder. Med Heal Sci J. 2010 Nov;3(3):30-9.

34. Shen IH, Lee TY, Chen CL. Handwriting performance and underlying factors in children with attention deficit hyperactivity disorder. Res Dev Disabil. 2012 Jul-Aug;33(4):1301-9. [PMID 22502858]

35. Rosenblum S, Epsztein L, Josman N. Handwriting performance of children with attention deficit hyperactive disorders. Phys Occup Ther Pediatr. 2008;28(3):219-34. [PMID 19064457]

36. Pollak Y, Shomaly HB, Weiss PL, Rizzo AA, Gross-Tsur V. Methylphenidate effect in children with ADHD can be measured by an ecologically valid continuous performance test embedded in virtual reality. CNS Spectr. 2010 Feb;15(2):125-30. [PMID 20414157]

37. Bart O, Podoly T, Bar-Haim Y. A preliminary study on the effect of methylphenidate on motor performance in children with comorbid DCD and ADHD. Res Dev Disabil. 2010 Nov-Dec;31(6):1443-7. [PMID 20650602]

38. Shaffer RJ, Jacokes LE, Cassily JF, Greenspan SI, Tuchman RF, Stemmer PJ Jr. Effect of Interactive Metronome® training on children with ADHD. Am J Occup Ther. 2001 Mar-Apr;55(2):155-62. [PMID 11761130]

39. Gol D, Jarus $T$. Effect of a social skills training group on everyday activities of children with attention-deficit-hyperactivity disorder. Dev Med Child Neurol. 2005 Aug;47(8):539-45. [PMID 16108454]

40. Segal R. Adaptive strategies of mothers with children with attention deficit hyperactivity disorder. Am J Occup Ther. 2000 May-Jun;54(3):300-6. [PMID 10842686]

41. Cronin AF. Mothering a child with hidden impairments. Am J Occup Ther. 2004 Jan-Feb;58(1):83-92. [PMID 14763639]

42. Wu YY, Huang YS, Chen YY, Chen CK, Chang TC, Chao CC. Psychometric study of the test of variables of attention. Psychiatry Clin Neurosci. 2007 Jun;61(3):211-8. [PMID 17472587]

43. Linder N, Kroyzer N, Maeir A, Wertman-Elad R, Pollak Y. Do ADHD and executive dysfunctions, measured by the Hebrew Version of Behavioral Rating Inventory of Executive Functions (BRIEF), completely overlap? Child Neuropsychol. 2010;16(5):494-502. [PMID 20521184]

44. Shen IH, Tsai SY, Duann JR. Inhibition control and error processing in children with attention deficit/hyperactivity disorder. Int J Psychophysiol. 2011 Jul;81(1):1-11. [PMID 21501634]

45. Brossard-Racine M, Majnemer A, Shevell MI. Exploring the neural mechanisms that underlie motor difficulties in children with attention deficit hyperactivity disorder. Dev Neurorehabil. 2011;14(2):101-11. [PMID 21410402]

46. Tsai LH, Meng LF, Hung LY, Chen HY, Lu CP. Coincidence of homophone spelling errors and attention problems in schoolchildren. Res Dev Disabil. 2011 Jan-Feb;32(1):75-80. [PMID 20951545]

47. Hahn-Markowitz J, Manor I, Maeir A. Effectiveness of cognitive-functional (cog-fun) intervention with children with attention deficit hyperactivity disorder. Am J Occup Ther. 2011 Jul-Aug;65(4):384-92. [PMID 21834453]

48. Shimoni M, Engel-Yeger B, Tirosh E. Executive dysfunctions among boys with attention deficit hyperactivity disorder (ADHD): performance-based test and parents report. Res Dev Disabil. 2012 May-Jun;33(3):858-65. [PMID 22230238]

49. Poulsen AA, Horswill MS, Wetton MA, Hill A, Lim SM. A brief office-based hazard perception intervention for drivers with ADHD symptoms. Aust N Z J Psychiatry. 2010 Jun;44(6):528-34. [PMID 20397782]

50. American Academy of Pediatrics Council on Children with Disabilities. Sensory integration therapies for children with developmental and behavioral disorders. Pediatrics. 2012;129(6):1186-9. 